\title{
Retail Image As Seen Through Consumers' Eyes: studying international retail image through consumer photographs of stores.
}

Steve Burt

Institute for Retail Studies

Department of Marketing

University of Stirling

Stirling, FK94LA, Scotland, UK

Email : s.l.burt@stir.ac.uk

Ulf Johansson*

Department of Business Administration

Lund University

PO Box 7080, SE-220 07 Lund, Sweden

Email: Ulf.Johansson@fek.lu.se

Åsa Thelander

Department of Service Management

Campus Helsingborg

Lund University

PO Box 882, SE-251 08 Helsingborg, Sweden

Email: asa.thelander@msm.lu.se

January 2007

*All correspondence should be directed to this author 


\title{
RETAIL IMAGE AS SEEN THROUGH CONSUMER'S EYES : STUDYING INTERNATIONAL RETAIL IMAGE THROUGH CONSUMER PHOTOGRAPHS OF STORES
}

\begin{abstract}
The aim of this paper is to explore how retail store image is perceived by consumers from different cultural backgrounds and with different degrees of awareness and experience of the retailer. The subject is IKEA, a retailer recognized as having a global approach to the markets in which it operates, resulting in a highly standardized approach to store branding. However, rather than employing traditional methodologies to elicit consumer perceptions of store image, we attempt to capture consumer perceptions through interpretations of the visual images generated by the participants themselves. The photoelicitation method employed captured the different interpretations and meanings attached to commonly identified elements of store image and reinforced the central role played by the store itself in retail image formation.
\end{abstract}

\section{KEYWORDS:}

retail image; IKEA; photo-elicitation; cross-culture 


\section{RETAIL IMAGE AS SEEN THROUGH CONSUMER'S EYES : STUDYING INTERNATIONAL RETAIL IMAGE THROUGH CONSUMER PHOTOGRAPHS OF STORES}

\section{Introduction}

Studies of retail image have a long history, starting with Martineau (1958). Research has covered many different aspects including customer perceptions of individual chains, malls, stores and departments within stores; and the contrasting perceptions of management and store personnel compared to those of customers (eg Manrai \& Manrai, 1995; McGoldrick, 1979; Hart \& Davies, 1996; Birtwistle et al, 1999; Zimmer \& Golden, 1988). During the past decade a new theme has been the image of international retail companies across different markets (McGoldrick \& Ho, 1992; McGoldrick, 1998; Burt \& Carralero-Encinas, 2000; Burt \& Mavrommatis, 2006). It seems logical that the challenges of managing a retail store image grow as the cultural differences between and within different individual consumer markets increase.

Retail image research is dominated by deductive approaches. The typical methods used, both in a national and international context, require respondents to answer a questionnaire with fixed answer alternatives. However, a fundamental problem with attitude scales - which most image surveys use - is that they involve a forced choice on pre-determined items/measures that do not necessarily comprise critical image components for the respondents themselves. In order to fully investigate consumer perceptions of a retailer's image the starting point should be their own criteria and perceptions. Consequently, a more inductive approach would seem relevant. This may be even more important in cross cultural research where we are dealing with consumers with different traditions, ideals and experiences. 
The concept of image in a marketing context has its origins in the 1950s. Although a commonly used term, image is recognized as a complex construct open to various interpretations. Image can be conceptualized from both a production and consumption perspective, but in both cases it is based on the premise that markets and consumer actions operate on impressions and perceptions of "reality". These in turn are derived from personal experiences and reference points, and are encapsulated in the meanings that consumers attach to various relationships with a brand. Image is invariably a subjective, personal, and consumer-centric concept. The symbolic, experiential, dimensions of brand image lead to questions as to how consumers "see" or “visualize” a brand, i.e. how they "picture” the brand.

\section{Aim and Objectives}

The aim of this paper is to explore how retail store image is perceived by consumers from different cultural backgrounds and with different degrees of awareness and experience of the retailer. The subject is IKEA, a retailer recognized has having a global approach to the markets in which it operates, resulting in a highly standardized approach to store branding. However, rather than employing traditional methodologies to elicit consumer perceptions of the store image, we attempt to capture perceptions through interpretations of visual images generated by the respondents themselves.

The objectives of this study are:

- to identify the constituent elements of store image as defined by consumers’ visual perceptions; 
- to assess if any visual perceptions of image transcend different cultural groups, and therefore represent core elements of the IKEA brand image;

- to assess how elements of image are perceived and evolve in respect of experience based reference points;

- to assess the potential of this methodological approach for research into retail image and international retail brand transfer.

The paper starts by reviewing how retail image has traditionally been conceptualized and measured, before debating the merits of approaches that explore visual imagery. The methodology employed in the study is then explained, and then the data collected is analysed. Conclusions are then drawn on the application of the methodology employed.

\section{Conceptualising and Measuring Retail Image: The Traditional Approach}

For most customers the key contact point with a retail organisation is the store - it is through their experiences of the store and the interactions that take place within the store that customers build relationships, and form their perceptions of a retailer. A positive store image has been identified as a key determinant of economic success (Jacoby \& Mazursky, 1984; Hildebrandt, 1988), store choice (Doyle \& Fenwick, 1974; Schiffman et al, 1977; Burns, 1992), and store loyalty (Mazursky \& Jacoby, 1986; Osman, 1993).

However, despite a long history the conceptualisation of store image is notoriously difficult (May, 1974). Consumer perceptions, built upon attitudes and opinions, are recognised as being situation and experience dependent (Berry, 1969), and highly subjective. Perceptions of store image vary across countries, geographical regions, 
market sectors, store formats, within a chain, and relative to existing competition (Marcus, 1972; Cardozo, 1974; Hansen \& Deutscher, 1977; Hirschman, et.al. 1978; Arnold et al, 1983; Oppewal \& Timmermans, 1997). Inevitably this leads to inconsistencies both in the conceptualisation and operationalisation of store image (Keaveney \& Hunt, 1992).

\section{conceptualisations of retail image}

Numerous attempts have been made to categorise the elements which contribute to store image. Martineau (1958), usually recognised as one of the first to consider store image as a source of competitive differentiation in retailing, identified four core attributes: layout and architecture; symbols and colour; advertising; and sales personnel. The review paper of Lindquist (1974) is often taken as the starting point in image research. Lindquist identified nine categories (merchandise; service; clientele; physical facilities; convenience; promotion; store atmosphere; institutional factors; and posttransactional satisfaction), which were themselves made up from a range of attributes. This listing has since been amended by Hansen \& Deutscher (1977) and Zimmer \& Golden (1988) amongst others, and McGoldrick (2002), provides a summary of 18 “general areas” comprising 90 “specific elements” used in previous image and brand identity studies.

Within these studies a distinction is often made between tangible and intangible factors. Martineau (1958) refers to the store "personality" as "the way in which the store is defined in the shoppers mind partly by the functional qualities and partly by an aura of psychological attributes". Similarly, Lindquist (1974) distinguishes between "functional qualities” and "psychological attributes” which included both physical (factual, 
functional, and tangible) and psychological dimensions, (formed as a result of the experience consumers have when exposed to a store). However, owing to the interpretative nature of image, this distinction is often seen as artificial and misleading. Oxenfeld (1974) argues that store image is a concept, which is:

"more than the sum of its parts..., it represents interaction among characteristics and includes extraneous elements..., it has some emotional content... a combination of factual and emotional material”.

In similar vein, Kapferer's (1986) identity prism combines functional and symbolic elements and stresses the importance of the customers' de-coding of these facets. Consequently, the interplay of tangible and intangible elements, and the meanings attached to them by customers based upon selective knowledge and past experiences, all contribute to the holistic construct of store image (Hirschman, 1981; Mazursky \& Jacoby, 1986).

\section{measurements of retail store image}

Given how it has been conceptualised, some form of attribute measurement provides the basis of most attempts to measure retail store image. Amirani \& Gates (1993) provide an overview of the different methodological approaches, which include: semantic differentials (eg Kelly \& Stephenson 1967, Hirschman et al, 1978; Menezes \& Elbert, 1979; Golden et al., 1987; Wong \& Tees, 2001); multi-dimensional scaling (eg Doyle \& Fenwick, 1974; Jain \& Etgar, 1976; Davies, 1987); conjoint and cluster analysis (eg Amirani \& Gates, 1993); multi-attribute modelling (e.g. James et al, 1976); and content analysis (eg Zimmer \& Golden 1988).

This range of measurement techniques has generated debate about the validity of the techniques themselves (McDougall \& Fry, 1974; Swan \& Futrell, 1980; and Wu \& 
Petroshius, 1987). More fundamentally, McGoldrick (2002) returns to the contradiction between conceptualisation and measurement noted by Keaveney \& Hunt (1992):

"Whereas the definitions and conceptualizations tend to emphasize the holistic nature of image, measures usually adopt the 'piecemeal', attribute-by-attribute approach: 'in short an image was believed to be a picture but was measured by a list'”

\section{Visualising Retail Image: Alternative Approaches}

Most research methods are focused on verbal statements. Researchers are familiar with texts and words and tend to prefer these forms despite the fact that many impressions are non-verbal, arising from visual, or other channels of perception. Through the use of other methods not so heavily dependent on words, we may gain clues to experiences derived from other senses, which are not self evident from verbal communication alone. Harper (2002) suggests that people respond in different ways to different forms of symbolic representations such as words and images. As in many other research fields visual methods in management are generally neglected (Prosser, 1998).

\section{the visual dimension}

Collier and Collier (1967) found combining photographs with talk in open-ended interviews, ie 'interviewing with photographs' a useful tool to obtain knowledge. Photographs act as a communication bridge between strangers, serve as a pathway to unfamiliar subjects, and as a "can-opener” for discussing the familiar. Interviewing with photographs also has implications for the interview situation. Photographs sharpen the memory and provide "external" stimuli, and attention is moved away from the faces of the participants to the photographs, which may reduce stress in the interview situation. Samuels (2004) argues that one can expect richer descriptions, grounded in the interviewees' own lived and affective experiences, rather than a simple listing of abstract 
qualities from such a method. Collier \& Collier (1967) also showed that visual stimuli could act as a reminder of impressions gained from other senses. Photographs may evoke memories of smell, sound and bodily experiences such as heat, which also constitute important components of an image. When impressions from different senses are recalled, the interviewee talks more freely about feelings that the situation, setting or place evokes. Abstract impressions are recalled, which would otherwise have been forgotten. Furthermore, in cross cultural research, when the researcher and the interviewee can be expected to have culturally distinct experiences and different degrees of exposure to a particular subject, an interview with photographs may be one way of bridging culturally distinct worlds.

The term photo-elicitation is used to describe studies where a combination of talk and photographs are used in an interview. There are different approaches to photoelicitation interviews depending on the origin of the pictures used (Rasmussen, 2004). By using photo-elicitation as an inductive approach, the researcher may be able to capture the way the interviewee makes meaning of specific phenomenon (Clark, 1999; ClarkIbanez, 2004). Participants are allowed to present their own worlds, which increases the chance of obtaining an insider perspective and discovering new and different patterns which might erase the researcher's own preconceptions (Samuels, 2004). There are many motivations to use pictures when studying image, but they are rarely used in studies of retail store image.

\section{the cultural dimension}

Cross-cultural research adds further challenges:

"It can pose challenges to scholars' preconceptions and is liable to be theoretically upsetting... (but its contribution) is not confined only to testing, validating and revising 
existing theory. It also has a more creative and innovative role - opening up new avenues” (Blumler et al., 1992 in Livingstone, 2003).

In social science, cross-cultural research has been debated on both epistimological and methodological grounds. A common complaint is that of ethnocentrism, a systematic bias where other nations or cultures are viewed through a western lens, so that the view of the researcher is privileged, and cultural specificity is neglected (Livingstone, 2003; Usunier, 1998). Adler (1983) distinguishes six different approaches to cross-cultural management research determined by the theoretical and managment issues to be addressed, the assumptions made about universality, and the ways similarity and differences are dealt with. Traditionally cross-cultural interviewing is defined as interviews across cultural and national borders (Ryen, 2002), but in a globalised world the concept may also be used for interviews with different ethnic groups within a single society.

Methodological critique is, naturally, related to epistemological standpoint. Also, practical issues are related to epistemology. One obvious difference between cultures is communication, both verbal and nonverbal. If the researcher and the researched have a language in common that can be used. In cross-cultural studies, English is often used as lingua franca. However if it is not the native language of the participants this may constitute a language barrier (Usunier, 1998). It may be difficult to establish the "correct" meaning of a word as words and phrases may mean different things in different cultural contexts. When words are combined into sentences they become a code, which may be even more difficult to translate as the combination may have a very particular meaning. Language also provides a speaker with a particular worldview. People from different cultures construct realities in different ways but translation offers the illusion of sharing the same vision of reality. Cross-cultural studies based on quantitative methods have been 
criticised for neglecting these problems. In studies using qualitative methods there are more opportunities to overcome some of these problems. Communication is not only verbal but also nonverbal, however, in most interview research nonverbal communication is ignored.

Methods which are not so heavily dependent on language alone, are a way of overcoming some of these problems. Photo-elicitation may be one way of bridging culturally distinct worlds. Although photographs can not replace nonverbal communication, a conversation over a photograph may relieve some of the pressure on verbal communication and language. The technique is often used when the informants lack written language or are preliterate, as in the case of young children (Johnson \& Weller, 2002). Despite the difficulties associated with cross-cultural research, in a period of retail globalization it is important to perform cross-cultural studies. The image of a "global" retailer can not be solely determined from the management perspective nor from studies undertaken in one culture. Comparative data is needed in order to understand different consumers' perceptions of an image.

\section{Methodology}

As indicated above, one objective of this study is to explore the potential of different research methodologies in the study of retail image. The method employed in this study builds on a combination of photography and interviews over photographs taken by the respondents at the request of the project team (autodriven photo-elicitation interviews). The subject was IKEA, selected as a retailer generally perceived as having a highly standardized market proposition in the countries in which it operates. 
To explore different cultural perceptions of visual imagery, participants were recruited to represent different cultural groups with different levels of exposure to the retailer. Four nationality based groups (Chinese, Greek, British and Swedish) each comprising six students participated. The Chinese and Greek students were chosen to represent countries where IKEA’s entry is recent. IKEA entered China in 1998 and Greece in 2001. At the time of the study in both of these markets the company had only two stores. The British group represented an established market, as IKEA entered in 1987 and now has13 stores. These three groups were based at a university in UK. The Swedish group was based at a Swedish university and represented the domestic market, where IKEA was founded in 1958, so awareness and experience of the retailer is very high despite the presence of only 14 stores.

The participants were between 20 and 25 years old, and represent the early nesters group. As students, irrespective of country, they originate from middle-class or higher middleclass homes and they were all living on a limited budget. Their life situations varied but home decoration was relevant to all, even if the degree of involvement differed, as all were living away from the parental home. The groups included both male and female participants, who were more or less equally represented among the groups. All interviewees were aware of IKEA. Experiences ranged from having heard about the company but never visited, to those who had furnished most of their apartment from the company.

The Glasgow store was used as the site for the Chinese, Greek and British participants, whilst in Sweden, the Malmö store was used. The stores were broadly similar in terms of sales area, assortment and frequency of customer visits and conformed 
to the standard IKEA layout and merchandising of stores. Inevitably there were some local differences between the stores, i.e., the exact composition of individual room settings.

Our intention is not to generalize the findings to represent the image of IKEA across all stores, but to test the value of the method for comparative research with participants from different cultural backgrounds.

Each student was given a disposable camera (27 pictures maximum) at the parking lot outside the store and asked to photograph "anything that made an impression on them” during their visit to the store. The participants were instructed to walk through the whole store and take photos individually - ie they should not negotiate with each other over which photographs to take. Some of them bought small items such as home decorations and kitchen utensils either for themselves or as gifts during their visit. In that sense the visit had similarities to a normal store visit.

The participants did not have the opportunity to plan which photographs to take in advance. All participants, with a few exceptions, felt that they had enough film to use. They went through the whole store and some returned to take photographs of things they had seen earlier in their visit. The participants remained on the site for between 1.5 and 2 hours.

Individual interviews took place within a few days of the store visits. Whilst time was needed to develop the photographs and to record them, the interviewees were still involved with the topic at the time of the interview. In the interviews the participants were asked a series of structured questions, with the intention of learning more about their photographs and their motives for taking them. The flow of the interviews was 
inspired by the Zaltman Methaphore Elicitation Technique (ZMET) (Zaltman \& Coulter, 1995; Zaltman, 1996). This is a method which uses semi-structured personal interviews around images that the interviewee has collected. The ZMET process is primarily designed for commercial settings but has been used in research as well, for instance to study perceptions of advertising (Coulter, Zaltman \& Coulter, 2001) and to study barriers to the adoption of 3G mobile banking services (Lee et al, 2003).

Based on this approach, the interviews followed the sequence of questions outlined in figure 1. Each step is intended to gain a deeper understanding of the interviewee's impressions of the store. According to Zaltman (1996) and Coulter et al (2001) these multiple steps serve to establish representations of the topic under investigation. In contrast to Zaltman and Coulter (1995), however, we do not claim that the photographs mirror inner thoughts or beliefs, rather it is a construction based on conventions, personal preferences limited and influenced by camera technique. The photographs are a medium of communication between the researcher and participant, and the steps have three objectives, namely reducing, categorizing and drawing conclusions, which is a standard procedure in qualitative analysis (see Huberman \& Miles, 1998). Step eight is a way to establish if there is a pattern of exclusion, if some topics are never photographed, or if there are settings when the camera is not used.

\section{INSERT FIGURE 1 HERE}

The procedure can be compared to a guided conversation about the respondents' photographs. The guide is a way to negotiate the meaning of impressions and as a way of collaborative accomplishment of image. The procedure is therefore not like an ordinary 
interview where the interviewer asks questions, the interviewee delivers answers, and the researcher interprets the answers. With this approach the interviewee starts the analysis and the aim is to achieve a mutal understanding of the impressions held about IKEA. The role of the researcher is in conducting the cross-case analysis.

Material generated by the ZMET-method is traditionally analysed in several steps (Zaltman and Coulter, 1995). First, interviews are transcribed and a text based analysis of transcripts undertaken to identify key themes or constructs. Previously unintended constructs are then added. The transcribed interviews are coded in terms of pairedconstruct relationships, where a construct pair is 'the causal relationship between two constructs' for example attractive/unattractive Following this, a consensus map is constructed, but only those themes mentioned by a third of the participants are included. In a later article (Coulter et al, 2001) a text based and image analysis of the summary images was added, and the two analyses were then compared. Triangulation across different researchers is always carried out.

One strength of the above papers is that the procedure is well described, which is not often the case with qualitative analyses. However, it is not clear how the non-verbal aspects of image were treated. The impression given is that only verbal statements were included in the analysis. Also the need for consensus before a theme was included in the analysis suggests that the focus was on similarities rather than differences. In our explorative study, it is the actual existence of a theme - which may reflect both similarities and differences - that is of interest, rather than the importance of a theme.

\section{Data Analysis}


Following the procedure outlined above, the data generated consisted of the participants' photographs of the IKEA stores, plus transcriptions of the interviews during which participants elaborated on their experiences and perceptions of the store visits. First, some comments about the photographs. All the participants were familiar with basic camera technique and the use of a camera did not seem to have created any difficulties. The participants used all of the 27 exposures available. Across the four groups a wide range of photographs was generated in terms of form and content. Most photographs were taken inside IKEA and ranged from overviews of the shop floor to details of specific products and services. Examples of photographs are shown in appendix 1. The technical composition of the photographs themselves presents a further avenue for analysis but that is not considered here.

Data analysis at this stage of the project is based upon the identified themes and the verbal comments made by the individual respondents about the photographs during the interviews. Analysis involved not just looking at the content of the photographs in isolation, but also considered what the participants said in the interviews. At this stage common observations and themes within the four groups became apparent. From this approach we can begin to see perceptions evolve as the context and meanings of the different photographs becomes clearer and interpretation easier. Private photographs are embedded in contexts, which the researcher can never fully understand from content analysis of photographs alone. Without the interview commentary, the richness of the customer’s own imagery is lost (Zimmer \& Golden, 1988).

\section{Identifying and interpreting elements of store image}


The emphasis throughout the analysis was on identifying similarities and differences between the four different groups. Similarities were sought to identify if any visual perceptions of image transcended the different cultural groups, and therefore represented core elements of the IKEA brand image. If only differences are sought, there is always a risk of exaggerating national stereotypes and overstating differences.

From the interview discussions there are some visual elements of image which seem to be important for all the participants (Appendix 1, Photograph 1). The room settings made an impression on all the groups and were considered to be an important element in image perception. There were a few room settings that particularly grabbed the attention of the interviewees - a bedroom, a kitchen and a set/decorated kitchen table. The participants talked about different aspects of the room settings, not just the furniture but also small details for instance pottery, posters and cushions that were in the rooms. Participants imagined themselves living in the different settings and considered whether the settings suited their own lifestyles. The room setting was regarded as an interactive environment were the store visitor could relate the products to his or her own life. Whilst looking at photographs of the room settings the participants talked about themselves, their own lives, homes, planned improvements etc..

However, the participants interacted with the room settings in different ways. For some it was an easy and almost self-evident activity. They placed themselves in the environment or they associated it with their friends' homes and decor. The Swedes were the only group who compared the room settings with images from the IKEA catalogue. The Chinese group also enjoyed the activity but found the room settings to be 'western style', too different and not appropriate to their own cultural context, for example: 
"Why I took this photo is because it is ridiculous. They put this furniture (a shoe shelf) in the room. It is for the shoes and it is put in a room! In China we won't put the shoes in the room. We think it smells so bad and it is very dirty to put in the room. Always we put shoes outside the door." (Chinese female)

Impressions were not limited to new ways of displaying furniture. The room settings were also attractive to the Swedes, who were very familiar with IKEA room setting displays. As the room settings are changed during the course of a year, they were an attraction even if the participant had been to IKEA before. When asked if they intended to show any of their photographs to someone else, the participants typically selected a photograph of a room setting.

Other important themes were decoration and labelling. These aspects themes related to the room settings and were changeable. Also it becomes evident that the same motif may mean different things to different participants. On the surface the participants photographed similar things, a motif appeared in several sets of photographs. But when participants talked about their photographs it was like opening a Pandora’s box - it was possible to talk about the deeper meanings which varied between the groups. This example also shows that when photographs are used it is possible to articulate meanings in a foreign language on a quite abstract level. Such practical issues have important epistemological consequences. It eases the situation for the participant, making it possible to see the store through their eyes.

Another common theme that appeared in several interviews, and amongst the photographs, was that of children. The participants talked about the children's department, the products for children and the crèche. But the meaning of this theme varied among the groups. For the Swedes and the British group this theme was about 
making the store experience enjoyable ie how IKEA helps ease the shopping experience when with children:

"Sure, they have nice children's products etc but the important thing was that they provided childcare and solutions allowing parents to shop for home furnishings in peace”. (Swedish male).

This was however seen in a different way by the Swedes than the other nationalities. The Swedes took the children theme for granted, and associated it with "classic IKEA” and their personal experiences from being a child at IKEA. This theme was, however, new to the Greek and Chinese groups who also found it interesting but in different ways. The Greek group found it an innovative and novel idea, the Chinese group found it unusual and reacted more with surprise:

"This is toys. It is very colourful. I just like it. If you look some toys are not very beautiful but if you look from far away it is eyecatching. Sometimes it is a bit stupid for me.

Interviewer : Stupid?

Ahh, for example...first I don't think toys are very useful. You can have but if you don't have it it is not necessary in your life. Personally I would not buy but it is nice when you see all of them gathering together and it is colourful. Maybe kids like but I don't" (Chinese female).

This Chinese participant considered the children's product range to be unnecessary, but she was still attracted to them as they were colourful. Colour is also a theme that several participants returned to. We are aware that colour preferences and associations are often regarded a culture bound phenomena. Therefore our focus was on references to colour per se rather than specific colours.

As in the quote above, some related colours to specific products whilst others talked about colour in relation to signs, display, decorations and room settings. Thus colour is a theme that cuts across several of the image categories listed in previous research (eg Lindquist, 
1974). The use of colour in both the store and individual products was felt to be very different from what was "normal” in China. However, this was seen positively, as well as a bit daring and non-traditional (with the emphasis depending on how western oriented a particular Chinese respondent’s home was.)

The restaurant provided another example of an impression that cuts across traditional image categories. Although it was not reported specifically as a theme, the interviewees talked about it in different contexts. The restaurant was considered to be a service to customers but was also referred to when IKEA was discussed in general. The participants recalled the taste of the food and one of the British participants showed a great deal of knowledge about different dishes. The Chinese also talked about the restaurant and photographed it as part of the exercise. Again, it was very different from what they were used to (the food, the setting, and the atmosphere) and was seen as positive element of the store.

All the participants talked about price but none reported it specifically as a theme. Despite this it was a recurrent topic and appeared in different contexts in the photographs. The participants referred to the prices as "good" and the products were seen as being “good value”/”cheap”.

We believe that these discussions over participant generated photographs added a further dimension to our interpretation of how the groups perceived the IKEA stores. From this exercise a number of common themes and potential universal subjects emerged. However, the participants showed that within these subjects the meanings attached to them varied ie the topic or theme might be constant, but interpretation and meanings varied. In the case of 'room settings' the Greek and the British groups 
associated this theme with non-traditional displays and the juxtaposition of individual products; the Chinese described the same subject in terms of more tactile references eg comfort, cozyness and softness, compared to the norm at home; whilst the Swedes, familiar with room settings, viewed them as providing solutions and inspiration. The British participants also talked about innovative solutions and modern design in relation to the room settings. They compared the furniture and the settings to traditional styles. A further example of different interpretations can be found in the case of 'children'. The Greeks and Chinese, referred to colour and new/different products for children, plus the fact that such a section/range would not be found at home, whereas the Swedes emphasised the process of shopping with children i.e. the crèche etc. We were, through this method, able to identify both cultural specificity and apparently universal themes. However, the universal themes were not as truly universal as they may at first appear. Different meanings and interpretations underpin similar positive or negative perceptions of the same themes.

\section{The importance of the learned context}

It was evident that the participants drew different experiences from the IKEA store visits and therefore their perceptions of the image varied. Consumer perceptions of a retailer's image are derived from multiple experiences : some may be personal, and others are mediated in some way. Different "stages" of image formation have been recognised by researchers in tourism studies. Gunn (1972) identified seven stages of image formation: accumulation, modification, the decision, travel, participation, return travel and new accumulation. The process starts with a simple or naive image of a destination which is enriched and modified when the tourists engages with different kinds 
of material relating to the destination. After a personal visit to the destination, the image will be based on personal experience and consequently will be further modified. Although these stages are related specifically to tourists' image of a destination they can be adapted and applied to a retail context. Gunn described the process in tourism as linear, but in a retail context when store visits are repeated and do not require significant investment in time nor money, the process can perhaps be more accurately thought of as circular. This process results in three types of image : organic image; induced image; and modified induced/complex image. The participants in this study can be identified as belonging to these different groups.

The Chinese participants’ image of IKEA could be described as an organic image. Their prior experience was limited. Some had heard about IKEA but most of them had not, and they did not mention any expectations or associations that they had before they went to the store. Some of them had friends or relatives that had visited IKEA. Therefore, the impressions that shaped their image were almost exclusively based on the actual visit to the store. During the interviews they talked about the store and the actual visit to IKEA Glasgow. When they wanted to put IKEA into context they compared the store to other furniture stores or to the furniture culture found in China. They talked about differences but also about specific products, decorations and displays which they found "strange”, and some even named "strange” as a specific theme. They also commented on a less positive aspect of store scale - lack of order. They felt that the size of the store led to displaced items and a lack of order which was recorded by photographs of misplaced items and mixed displays of products. Many things were quite different to what they were used to, so they were confused and talked about how they 
tried to figure out how a piece of furniture was supposed to work. When prompted, the Chinese participants typically arranged their photographs in order as in a photograph album and wanted to show them to their friends. They intended to show all the photographs to their friends and/or family.

The Greek participants’ image can best be described as developed organic or induced image. Some of them had former experiences of IKEA, either from a previous visit or having heard of/read about IKEA. Compared to the Chinese group they had more experience, although IKEA entered the Greek market later. Still, however, their impressions were heavily based on the actual visit. When IKEA was put into context they compare the actual visit to IKEA Glasgow to visits to IKEA in Athens or Thessaloniki. They talked about IKEA in an IKEA context and the store was not regarded as a strange concept per se. But there were products and items that puzzled them. One respondent commented:

"IKEA sells decorative stones. What Greek would buy stones?! You just go down to the beach and pick them up". (Greek male)

Most held positive views about product variety, especially the variety of décor products (not the furniture). They felt that the photographs were worth showing to their friends and family.

In general the British participants could be considered to have an induced image. Like the other groups, they had heard about IKEA from family and friends and they had personal experience. But also they talked more about mediated experience which had enriched their perceptions of image. They talked about impressions from IKEA advertisements and news articles. Their reference points were their experiences from the 
actual visit and the mediated image with which they compared the visit. When one of the participants was asked to pick the most representative photograph he chose two.

"Before I stepped into the store I would probably expect something like that (Appendix 1, photograph 2). It shows the cheap price and shows the product, the colour as well and it is plain design. It is my impressions before I went to the store. Probably afterwards it would be something like this (Appendix 1, photograph 3). The products are in there as well but how they have created just a really nice comfort sitting room, a family sitting room with a dining table as well. I would think of IKEA as something like that more now”. (British male)

This participant talked about his expectations and how they were confirmed during the visit, but he also discussed new impressions and how his image had been modified and enriched. The participants took photographs that confirmed their expectations as well as photographs representing new and unexpected impressions. Thus their impressions were not limited to the actual visit, former visits or the store, they were enriched and are more abstract. The British participants talked openly about the IKEA concept, the uniqueness of the concept, Swedishness and what they considered to be typical Swedish design and typical IKEA. Their impressions were mainly positive and there were few puzzled or confused impressions compared to the Chinese and Greek groups. They had accepted the concept and going to IKEA was regarded as a mundane experience, so the photographs did not qualify as being special enough to put into a photo album to be shown to others or to be kept for personal use.

The Swedish participants’ image can be described as a complex image. Their impressions were not exclusively related to the actual visit to IKEA. The institutionalization of IKEA for the Swedes underpinned the interviews and all the Swedish participants had extensive experience of IKEA. They talked about childhood daytrips with their family and what they always bought at IKEA. 
"I took this one because when I was a child we went to Älmhult and it was a daytrip for the whole family. We had lunch there as it took almost an hour to get there. The picture is of the meatballs as that is the dish we ate, meatballs and lingonberry. After that we got an ice-lolly." (Swedish female)

They were so familiar with IKEA that when asked to take photographs of what made an impression on them - they took photographs that "represented IKEA" and which could be used to explain the special features of IKEA to others (Appendix 1, photograph 4). They knew the names of products which have been there for years (eg Klippan, Billy etc), as well as the room settings and solutions particularly the 'Startpaket' (a kitchen essentials start pack for people moving away from the home).

Without prompting, the Swedes talked about IKEA in the newspapers, about products they had seen in home décor magazines, and about the IKEA catalogue. Thus, their image was heavily based on former experiences and many other sources - some of which they were not aware of themselves. IKEA was well integrated in their daily lives and they talked about IKEA in a different way than the other groups. They were knowledgeable about the concept, they talked about strategies and distinguished between classics and innovations. Their perceptions of image were nuanced in that they concurrently held both positive and negative opinions about different aspects. 'On the other hand' and 'but when considering...' were phrases that appeared during the interviews. The Swedes were the only group of participants who reported negative experiences. When they were asked if they wanted to put their photographs into an album or to show them to others, they thought that this was a ridiculous request - as no one would be interested in them.

The analysis therefore suggests that perceptions of store image evolve in phases. Participants in early stages of the image formation process talked exclusively about store image, as their experience of IKEA was solely based on the impressions from the store 
itself. Those in the later stages of the image formation process did not just talk about impressions from the store visit alone but also about IKEA as a broader concept, like a brand. The Swedish and British groups, which belong to the later stages, talked about the store as one source of information amongst others, and how impressions from the store visit either confirmed (and developed) or contradicted their previously established image perceptions. Thus, the role of the store as an agent of image formation changes during the phases. First it is the main source of image, and later it confirms or modifies image. However, the store is the most important agent throughout the process. The store is regarded as the true image of IKEA, as the place where everything comes together, and as the only way to get to know IKEA. When they found that their expectations did not correspond with the impressions gained during the store visit, they modified their image. Thus impressions gained from the store can be considered to be the superior element in image formation.

\section{Assessment of the Research Method}

The current exploratory study has demonstrated the potential for using photographs taken upon request by respondents as a means of assessing store image in a cross cultural context. Several of the advantages of using photographs as stimuli for a guided conversation that have been pointed out in previous research have been confirmed. For example, how photographs can provide a reminder of other impressions and emotions. In this study, the photographs stimulated comments on : aural (sounds) and tactile (feel of textiles) perceptions; abstract impressions such as sense of time and light that create a mood or atmosphere; bodily experiences such as tiredness; and embedded 
values such as childishness. All of these additional impressions contribute to image building but are difficult to identify from traditional questionnaire or interview techniques. Photo elicitation interviews are thus not limited to only identifying visual elements of store image.

Another important advantage is that an interview over photographs relieves stress and encourages the interviewee to talk about perceptions of the store from his/her viewpoint. An interview over photographs moves attention from language, grammar and phrasing. During the viewing activity it is not necessary to be absolutely fluent in the particular language. Thus it is quite natural to utter a few words or sentences, look at a photo in silence and then add a few words or sentences without feeling awkward. This form of conversation gives the interviewee time to think, and to find words to express him or herself. Even more important, it becomes evident that language is not only about finding the right words but is also about structuring ways of thought. Words may evoke different connotations to people which are difficult to discover during an ordinary face to face interview. When photographs are used they may reveal these linkages. When the interviewer and the interviewee are looking at the same photograph and it is discussed, differences in perception and meaning can be defined and understood. We believe that in this cross-cultural study some of the advantages of the method have proved to be extremely important on both practical and epistemological grounds.

Compared to previous research, where image is measured by a list this methodological approach makes it possible to get an insider's perspective. Some of the impressions reported correspond to those typically found in categorizations whilst others are not considered to be important. This approach makes it possible to identify other 
aspects important for image formation, such as prior experience and reference points. Also it makes it possible to identify core elements that change or modify the perceptions of IKEA and how impressions from different sources are negotiated.

As with all methods, there are shortcomings. In this case, it is the "missing" impressions or settings that the participant could not photograph for various reasons. Although the participants took photographs to represent their impressions, they reported one specific difficulty, namely taking photographs of other people. Taking photographs of other customers or of store personnel appeared to be awkward, at least for some of them. The participants overcame this problem as they found other motifs in the store to represent the same impression. Thus, when looking through the photographs it is obvious that pictures of people are absent. However store personnel and other customers appear in their stories. One might argue that interaction with personnel may not be a dominating theme at IKEA as the concept is built upon self-service, or that the participants were not involved in a direct purchasing activity that would involve person to person interaction. However, in this study it seems that during the visit the participants were aware of various "additional" impressions and found ways to represent them in photographs, so that they could remember them during the interview. This again reflects the flexibility and fluidity of the method as a means of exploring emotive, relational, impressions of a store.

\section{Conclusions}

The staring point for this study was the apparent contradiction between the recognition that retail store image is a holistic, relational construct, ultimately based upon 
consumer perceptions of "reality" (and as such is highly subjective and personal), yet it is invariably measured by attributes based upon pre-determined items. These issues are further amplified in the case of retail companies expanding on the global stage, where consumer perceptions are grounded in cultural norms and experiences. Given this, we explore the potential of alternative techniques, namely photo elicitation - the combination of visual stimuli and verbal discussion - to explore consumer perceptions of retail store image, across different cultures.

The photo-elicitation method provides valuable clues to the store image formation process. In addition to capturing any variations in perceptions which might arise from cultural differences between the four groups represented in the study, the participants also had different levels of awareness and experience of IKEA. The inclusion of Swedes captured views from the domestic market, where the company is well known and ingrained into the retail infrastructure, whereas for the Greek and Chinese interviewees IKEA is a relatively "new” arrival ie experience of the store was low. The British group represented a "half-way house" where IKEA is an established element of the retail fabric.

The method also allowed identification of both universal and unique elements of the IKEA store image. This implies that the company image is based upon a combination of “core” universally recognizable elements which contribute to image, and culture specific elements, which take on greater importance in specific markets. More importantly, for our understanding of store image, the technique captured different interpretations and meanings attached to similar subjects/objects. Thus, an element of image may appear to be a constant but it can be interpreted in different ways. Whether different interpretations are due to cultural (in the widest sense) differences or familiarity 
with a store image requires further investigation. There is some evidence from this study that as familiarity increases over time the underlying basis of impressions moves from the "difference" or "shock" impact of something new (and innovative) with a focus on form, to a more process view of image. Also the role of the store as an agent of image formation changes over time. These findings have implications for brand transfer from one market to another.

We believe that this exploratory study has shown the value of photo elicitation methods in deriving the meaning attached to objects. Furthermore, it prompts recall of experiential elements of perceptions and stimulates views based on other senses. As such it adds value to the traditional attitude scale measures found in store image research. One potential drawback of the method is a difficulty in photographing service interactions between people, but the use of photographs in an interview situation allowed for the prompting of "missing" interpretations which drew comment on these situations. 


\section{References}

Adler, N. J. (1983) A Typology of Managment Studies involving Culture, Journal of International Business Studies, 14(2), pp. 29-47

Amirani, S. and Gates, R. (1993) An Attribute-Anchored Conjoint Approach to Measuring Store Image, International Journal of Retail and Distribution Management, 21(5), pp. 30-39.

Arnold, S.J., Oum, T.H. and Tigert, D.J. (1983) Determinant Attributes in Retail Store Patronage: seasonal, temporal, regional, and international comparisons, Journal of Marketing Research, 20(2), pp. 149-157.

Berry, L.L. (1969) The Components of Department Store Image: a theoretical and empirical analysis, Journal of Retailing, 45(1), pp. 3-20.

Birtwistle, G., Clarke, I. and Freathy, P. (1999) Store Image in the UK Fashion Sector: Consumer verses Retailer Perceptions, International Review of Retail Distribution and Consumer Research, 9(1), pp. 1-16.

Burns, D.J. (1992) Image Transference and Retail Site Selection, International Journal of Retail \& Distribution Management, 20(5), pp.38-44.

Burt, S. and Carralero-Encinas, J. (2000) The Role of Store Image in Retail Internationalization, International Marketing Review, 17(4/5), pp. 433-453.

Burt, S. and Mavrommatis, A. (2006) The International Transfer of Store Brand Image, International Review of Retail Distribution and Consumer Research, 16(4), pp. 395-413.

Cardozo R. (1974) How Images Vary by Product Class, Journal of Retailing, 50(4), pp. 85-98.

Clark, C. D. (1999) The Autodriven Interview: a photographic viewfinder into children's experiencees”. Visual Sociology, 14, pp.39-50.

Clark-Ibanez, M. (2004) Framing the Social World With Photo-Elicitation Interviews American Behavioral Scientist, 47(12), pp.1507-1527.

Collier, J., and Collier, M. (1967) Visual Anthroplogy: Photography as a Research Method. (Rev. and exp. Edition) Albuquerque: University of New Mexico Press.

Coulter, R.A., Zaltman, G., and Coulter, K. S. (2001) Interpreting Consumer Perceptions of Advertising: an application of the Zaltman Methaphor Elicitation Technique, Journal of Advertising, 30(4), pp.1-21.

Davies, G. (1987) Monitoring Retailing Strategy by Measuring Customer Perception, in G. Johnson (ed.), Business Strategy and Retailing, Wiley : Chichester

Doyle, P. and Fenwick, I. (1974) How Store Image Affects Shopping habits in Grocery Chains, Journal of Retailing, 50(4), pp. 39-52.

Golden, L.L., Albaum, G., and Zimmer, M.R. (1987) The Numerical Comparative Scale: an economical format for retail image measurement, Journal of Retailing, 63(4), pp. 393-410

Gunn, C.A. (1972) Vacationscape - Designing Tourist Regions. Austin, Texas: University of Texas.

Hansen, R.A., and Deutscher, T. (1977) An Empirical Investigation of Attribute Importance in Retail Store Selection, Journal of Retailing, 53(4), pp. 59-72.

Hart, C.A. and Davies, M.A.P. (1996) Consumer Perceptions of Non-Food Assortments: an empirical study. Journal of Marketing Management, 12(4), pp. 297-312. 
Harper, D. (1998) On the Authority of the Image: visual methods at the crossroads”. in Denzin, N. K. and Lincoln, Y. S. (Eds.), Collecting and Interpreting Qualitative Materials. London: Sage.

Harper, D. (2002) Talking About Pictures: a case for photo elicitation, Visual Studies, 17(1), pp.13-26.

Hildebrandt, L. (1988) Store Image and Perception of Performance in Retailing, Journal of Business Research, 17, pp 91-100.

Hirschman, E. (1981) Retail Research and Theory, in Enis, B.M., and Roering K.J., (eds), Review of Marketing, Chicago: American Marketing Association

Hirschman, E., Greenberg, B. and Robertson, D. (1978) The Intermarket Reliability of Retail Image Research: an empirical examination, Journal of Retailing, 54(1), pp. 3-12.

Huberman, A.M. and Miles, M.B. (1998) Data Management and Analysis Methods, in Denzin, N. K. and Lincoln, Y. S (eds.) Collecting and Interpreting Qualitative Materials. London: Sage.

Jacoby, J. and Mazursky, D. (1984) Linking Brand and Retail Image - Do Potential Risks Outweigh the Potential Benefit?, Journal of Retailing, 60(2), pp. 105-122.

Jain, A.K. and Etgar, M. (1976) Measuring Store Image through Multi-Dimensional Scaling of Free Response Data, Journal of Retailing, 52(4), pp. 61-70.

James, D.L., Durand, R.M. and Dreves, R. (1976) The Use of a Multi-Attribute Model in a Store Image Study, Journal of Retailing, 52(2), pp. 23-34.

Johnson, J.C. and Weller, S.C. (2002) Elicitation techniques for interviewing. in J. F. Gubrium, J.F. and Holstein, J.A. (eds) (2002) Handbook of Interview Research. London: Sage.

Kapferer, J-N. (1986) Beyond Positioning: Retailer's Identity, Retail Strategies for Profit and Growth, Seminar Proceedings, ESOMAR: Amsterdam, pp.167-75.

Keaveney, S.M. and Hunt, K.A. (1992) Conceptualization and Operationalization of Retail Store Image: a case of rival middle-level theories, Journal of The Academy of Marketing Science, 20(2), pp. 165-175.

Kelly, R. and Stephenson, R. (1967) The Semantic Differential: an information source for designing retail patronage appeals, Journal of Marketing, 31(4) Part I, pp. 4347.

Lee, M. S.Y., McGoldrick, P., Keeling, K.A., and Doherty, J. (2003) Using ZMET to Explore Barriers to the Adoption of $3 G$ Mobile Banking Services. International Journal of Retail \& Distribution Management, 31(6), pp. 340-348.

Lindquist, J.D. (1974) Meaning of Image: a survey of empirical and hypothetical evidence, Journal of Retailing, 50(4), pp. 29-38.

Livingstone, S. (2003) On the Challenges of Cross-National Comparative Media Research, European Journal of Communication, 18(4), pp. 477-500.

Manrai, A.K. and Manrai, L.A. (1995) A Comparative Analysis of Two Models of Store Preference Incorporating the Notion of Self-Image and Store Image: some empirical results, Journal of Marketing Channels, 4(3), pp. 33-51.

Marcus, B.H. (1972) Image Variation and the Multi-Unit Retail Establishments, Journal of Retailing, 48(2), pp. 29-43.

Martineau, P. (1958) The Personality of the Retail Store, Harvard Business Review, 36 (January/February), pp. 47-55. 
Mazursky, D. and Jacoby, J. (1986) Exploring the Development of Store Images, Journal of Retailing, 62(2), pp.145-165.

May, E.G. (1974) Practical Applications of Recent Retail Image Research, Journal of Retailing, 50(4), pp.15-20, 116.

McDougall, G.H.G. and Fry, J.N. (1974) Combining Two Methods of Image Measurement, Journal of Retailing, 50(4), pp. 53-61.

McGoldrick, P. (1979) Store Image: how departmental images differ in a variety chain. Retail \& Distribution Management, 7(5), pp. 21-24.

McGoldrick, P. and Ho, S.L. (1992) International Positioning: Japanese department stores in Hong Kong, European Journal of Marketing, 26(8/9), pp. 65-73.

McGoldrick, P. (1998) Spatial and Temporal Shifts in International Retail Images, Journal of Business Research, 42, pp.189-196.

McGoldrick, P. (2002) Retail Marketing. $2^{\text {nd }}$ edition. London : McGraw-Hill

Menezes, D. and Elbert, N.F. (1979) Alternative Semantic Scaling Formats for Measuring Store Image: an evaluation, Journal of Marketing Research, 16 (February), pp. 80-87.

Oppewal, H. and Timmermans, H. (1997) Retailer Self-Perceived Store Image and Competitive Position, International Review of Retail Distribution and Consumer Research, 7(1), pp. 40-59.

Osman, M. (1993) A Conceptual Model of Retail Image Influence on Loyalty Patronage Behaviour, International Review of Retail, Distribution and Consumer Research, 3(2), pp. 33-48.

Oxenfeld, A.R. (1974) Developing a Favourable Price-Quality Image, Journal of Retailing, 50(4), pp. 8-14, 115.

Prosser, J. (1998) The Status of Image-based Research, in Prosser, J. (ed.) Image-based Research: a sourcebook for qualitative researchers. London: Routledge.

Rasmussen, K. (2004) Fotografi och Barndomssociologi, in Aspers, P., Fuehrer, P. and Sverrisson, A. (eds.) Bild och Samhälle: visuell analys som vetenskaplig metod. Lund: Studentlitteraur.

Ryen, ?. (2002) Cross-Cultural Interviewing, in Gubrium, J.F. and Holstein, J.A (eds.), Handbook of Interview Research, London: Sage.

Samuels, J. (2004) Breaking the Ethnographer's Frames, American Behavioral Scientists, 47(12), pp.1528-1550.

Schiffman, L., Dash, J. and Dillon, W. (1977) The Contribution of Store-Image Characteristics to Store Type Choice, Journal of Retailing, 53(2), pp. 3-14, 46.

Swan, J.E. and Futrell, C.M. (1980) Increasing the Efficiency of the Retailer's Image Study, Journal of the Academy of Marketing Science, 8, pp. 51-57.

Usunier, J-C. (1998) International \& Cross-Cultural Management Research. London: Sage.

Wong, J.K. and Tees, R.K. (2001) A Test of the Stability of Retail Store Image Mapping Based on Multi-Entity Scaling Data, Journal of Retailing and Consumer Services, 8(2), pp. 61-70

Wu, B.T.W. and Petroshius, S.M. (1987) The Halo Effect in Store Image Measurement, Journal of the Academy of Marketing Science, 15, pp. 44-51

Zaltman, G. (1996) Metaphorically Speaking: new technique uses multidisciplinary ideas to improve qualitative research, Marketing Research, 8(2), pp.13-20 
Zaltman, G. and Coulter, R.H. (1995) Seeing the Voice of the Consumer: metaphorbased advertising research, Journal of Advertising Research, 35(4), pp.35-51.

Zimmer, M.R. and Golden, L.L. (1988) Impressions of Retail Stores: a content analysis of consumer images, Journal of Retailing, 64(3), pp. 265-293. 


\section{Figure 1 : Interview Questions and Sequence}

The respondents were :

1. asked, at the start of the interview, if they had visited IKEA before;

2. handed the pack of photographs and given the opportunity to look through them and comment on them;

3. asked to choose 12 photographs from their pack and asked to talk about the selected and rejected photographs;

4. asked to arrange the photographs in themes and to give names to these different themes;

5. asked to rank the themes in order of importance and also to say whether it was a positive or a negative theme;

6. asked to pick out the most representative photo of their visit to the store;

7. asked, towards the end of the interview, to arrange their photos as they would if they were to tell a friend about the visit to IKEA;

8. asked, at the end of the interview, if there were things that they had not been able to photograph but which had made an impression (ie something important but they had found it difficult to take pictures of because of socialized constraints, and/or things they wanted to photograph but had run out of film). 
Appendix 1: Sample of Photographs Taken by the Participants

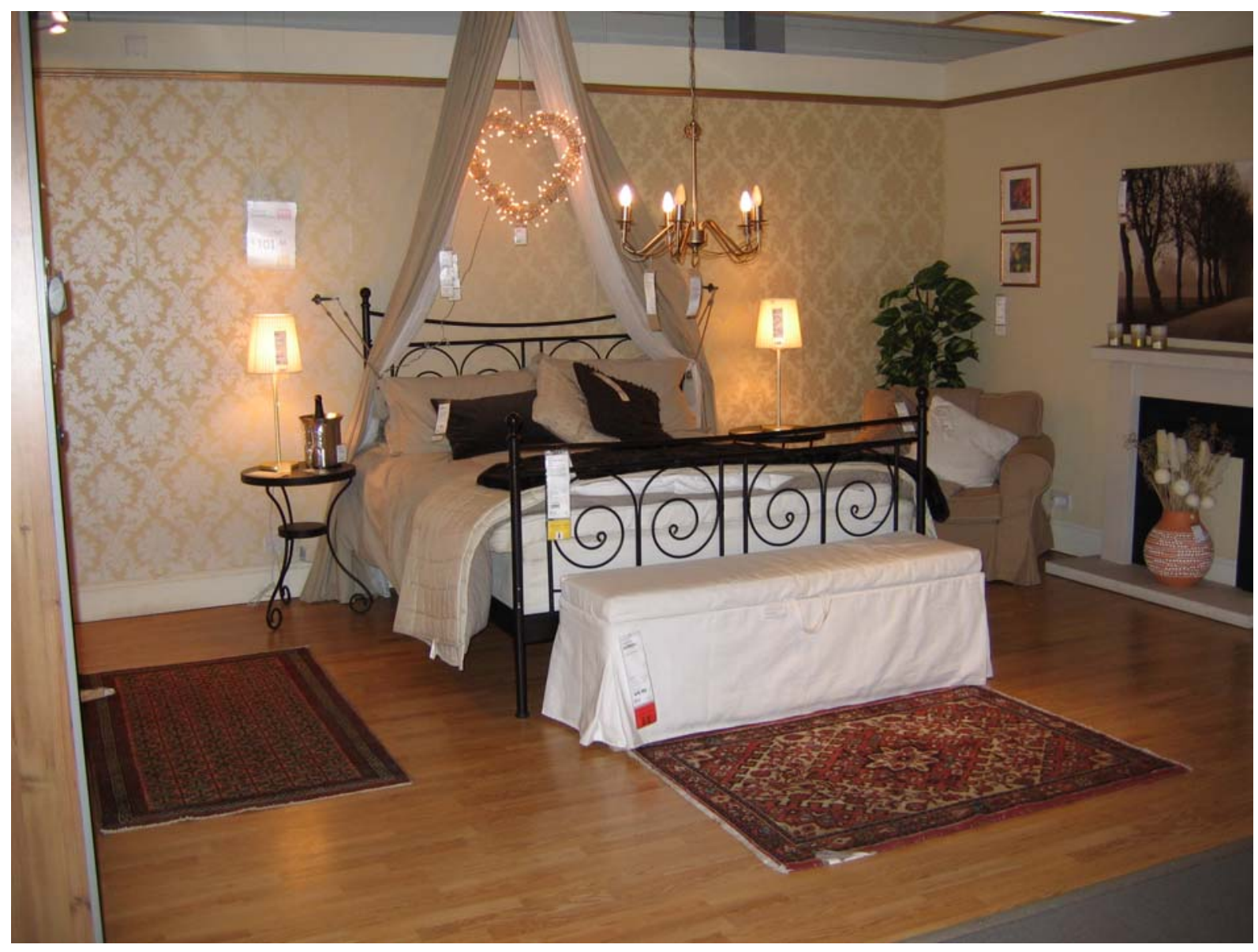

Photograph 1. An example of a photograph representing “Room Settings”. 


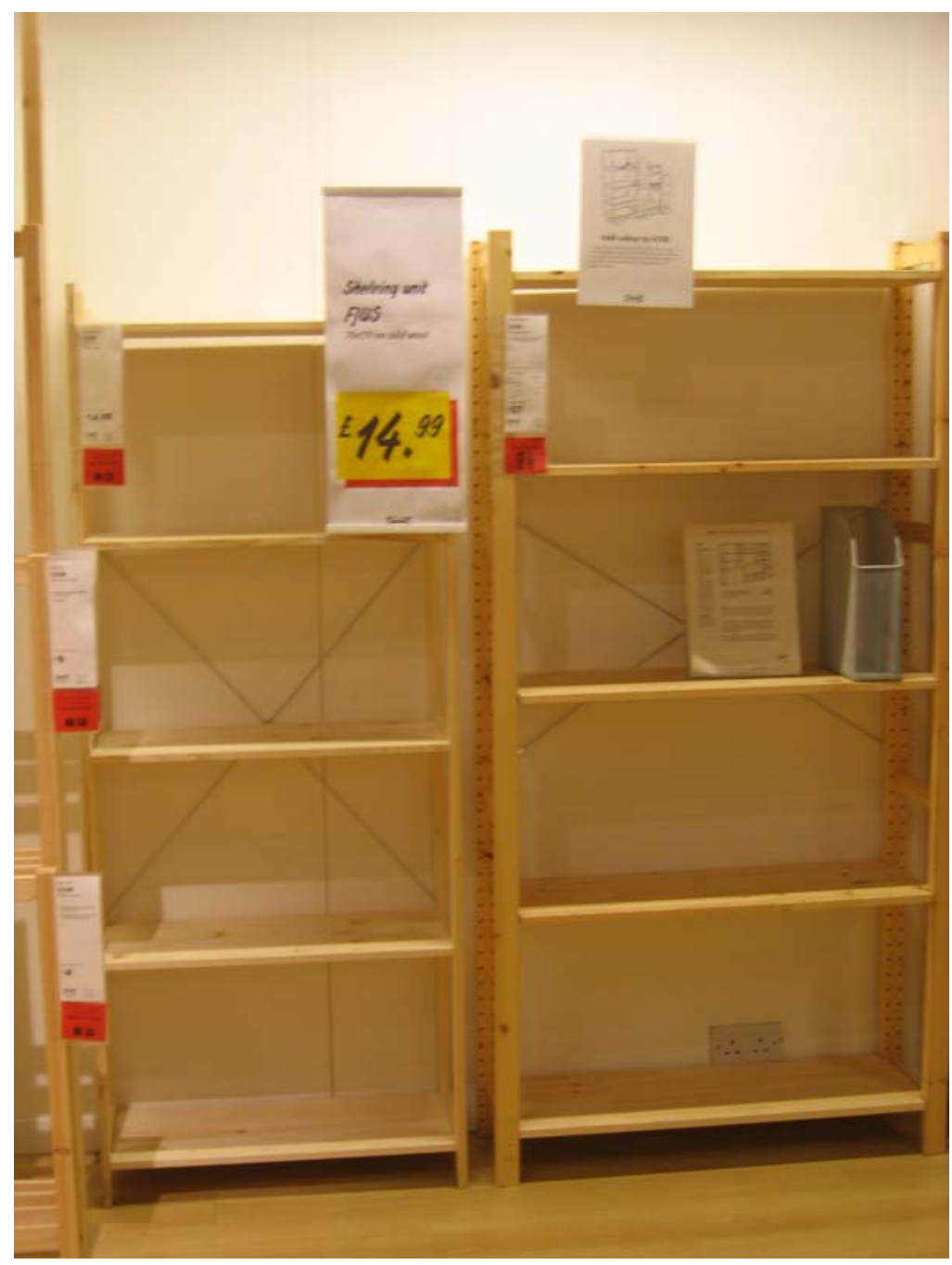

Photograph 2. A photograph representing the image of IKEA before the visit to the store (British male). 


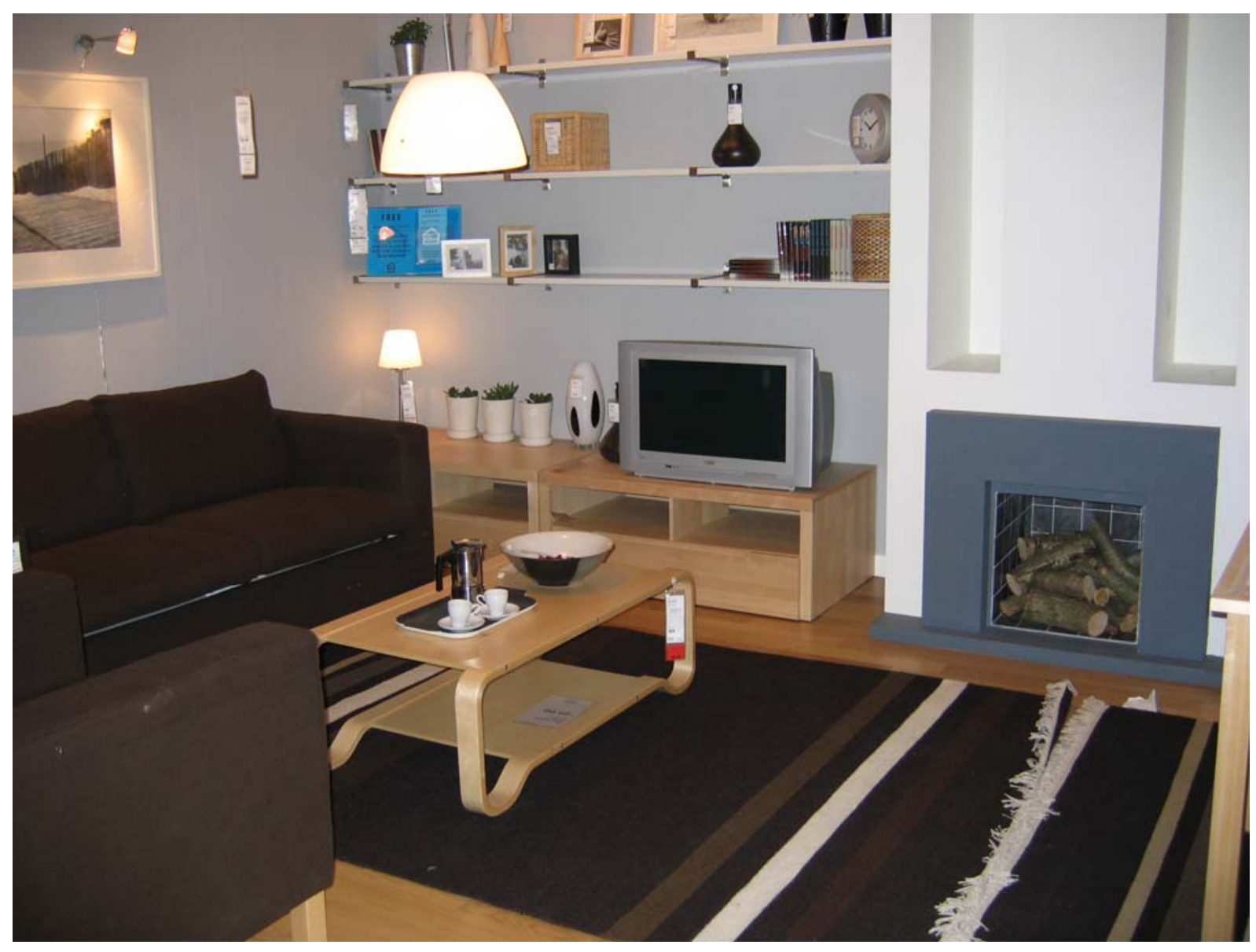

Photograph 3. A photograph representing the image of IKEA after the visit to the store (British male). 


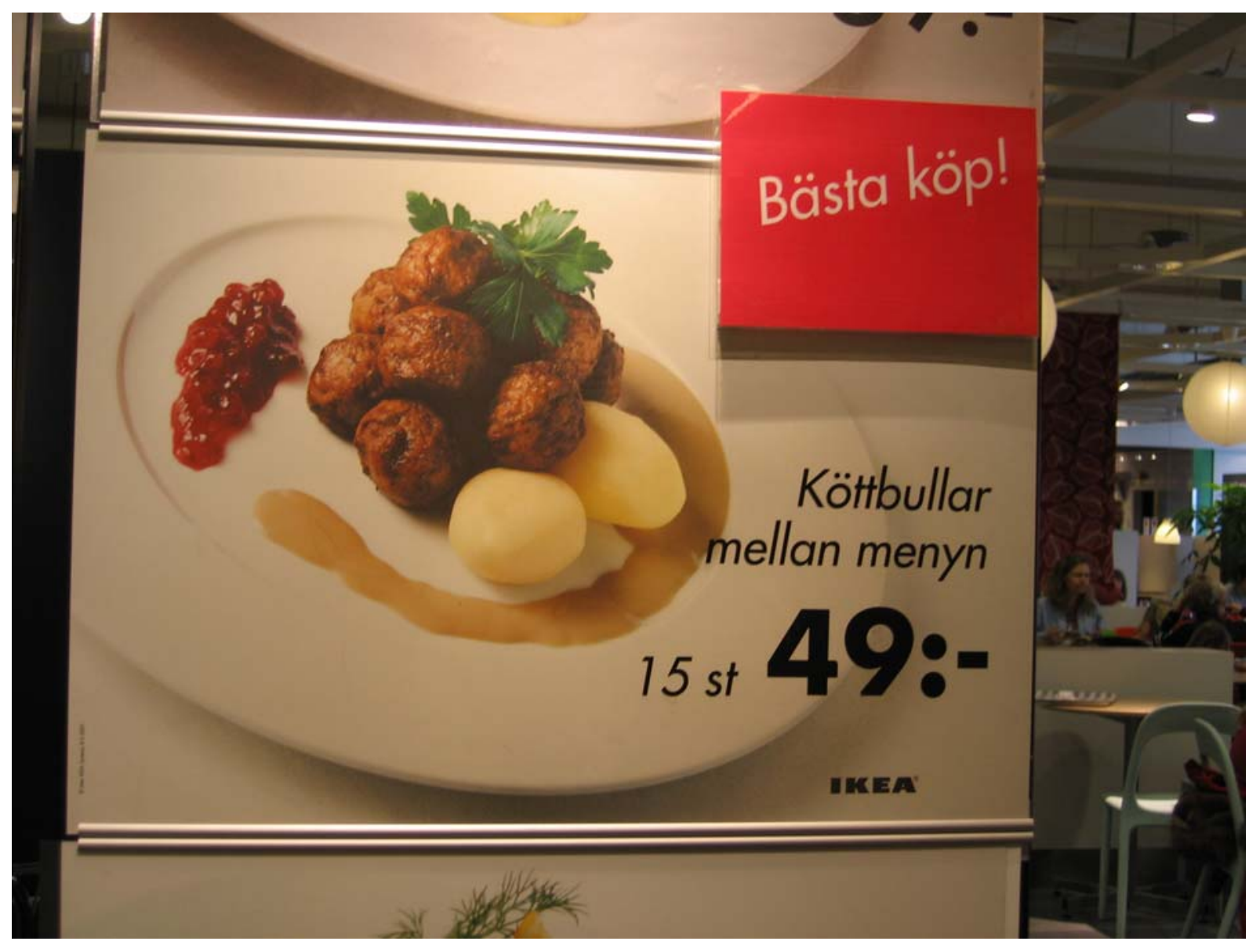

Photograph 4. A photograph representing 'IKEA Classics' (Swedish female). 